\title{
Acute and Sub-Acute Antihypertensive Effects of Syzygium polyanthum Leaf Extracts with Determination of Gallic Acid using HPLC Analysis
}

\author{
Azlini Ismail ${ }^{1 *}$, Nurul Syahida Ramli ${ }^{2}$, Mahaneem Mohamed ${ }^{3}$, Wan Amir Nizam Wan Ahmad ${ }^{2}$
}

\section{Azlini Ismail ${ }^{*}$, Nurul Syahida Ramli², Mahaneem Mohamed ${ }^{3}$, Wan Amir Nizam Wan Ahmad $^{2}$}

\section{'Department of Fundamental Dental and Medical Sciences, Kulliyyah of Dentistry, International Islamic University Malaysia, Kuantan Campus, Indera Mahkota, Kuantan, Pahang, MALAYSIA. ${ }^{2}$ Biomedicine Program, School of Health Sciences, Health Campus, University Sains Malaysia, Kubang Kerian, Kelantan, MALAYSIA. \\ ${ }^{3}$ Department of Physiology, School of Medical Sciences, Health Campus, University Sains Malaysia, Kubang Kerian, Kelantan, MALAYSIA. \\ Correspondence}

Azlini Ismail

Department of Fundamental Dental and Medical Sciences, Kulliyyah of Dentistry, International Islamic University Malaysia, Kuantan Campus, Indera Mahkota,

Kuantan, Pahang, MALAYSIA

Phone no : +60-14-5010081

E-mail: dr_azlini@iium.edu.my

History

- Submission Date: 01-03-2018.

- Revised Date: 14-03-2018;

- Accepted Date: 19-04-2018

\section{DOI : 10.5530/pj.2018.4.109}

Article Available online http://www.phcogj.com/v10/i4

\section{Copyright}

(c) 2018 Phcog.Net. This is an openaccess article distributed under the terms of the Creative Commons Attribution 4.0 International license.

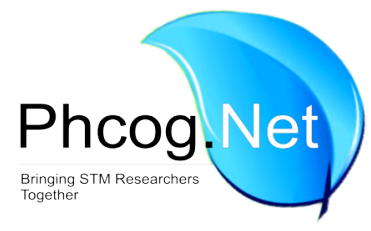

\begin{abstract}
Context: Aqueous decoction of Syzygium polyanthum (ADSP) leaf is one of Malay traditionalremedial-preparations for hypertension. Intravenous ADSP reduced blood pressure of anesthetized Wistar-Kyoto (WKY) and Spontaneously-Hypertensive rats (SHR); however, acute and sub-acute effects of oral ADSP on conscious rats and its bioactive compound(s) are not comprehensively studied. This study aims to examine the acute and sub-acute effects of ADSP in comparison to methanol extract (MESP) on systolic blood pressure (SBP) of conscious WKY and SHR rats, as well as to identify their major phenolic-compound using highperformance-liquid-chromatography (HPLC). Methodology: For acute study, SHR and WKY rats were gavaged with single-dose of ADSP or $\operatorname{MESP}(2.00,2.50$ or $3.00 \mathrm{~g} / \mathrm{kg})$, vehicles, or losartan $(0.01 \mathrm{~g} / \mathrm{kg})$. SBP was measured after 1, 3, 5, 6 and 24 hr-post-administration. For subacute experiment, SHR rats were gavaged once-daily with ADSP or MESP $(2.50 \mathrm{~g} / \mathrm{kg} / \mathrm{day})$, vehicles, or losartan $(0.01 \mathrm{~g} / \mathrm{kg} /$ day $)$ for 3-week and their SBP was weekly-measured. Phenolic compounds were screened using ferric-chloride test, then gallic acid was determined using HPLC. Results: Acute administration of ADSP (2.50 to $3.00 \mathrm{~g} / \mathrm{kg}$ ) and MESP $(2.00$ to $3.00 \mathrm{~g} /$ $\mathrm{kg}$ ) significantly reduced SBP of SHR, but not of WKY rats. Repeated-daily-dose administration of MESP $(2.5 \mathrm{~g} / \mathrm{kg} /$ day) significantly reduced SBP of SHR after 2-week and sustained until 3-week, while ADSP ( $2.5 \mathrm{~g} / \mathrm{kg} /$ day) significantly reduced SBP only after 3-week. Gallic acid was the major phenolic-compound in ADSP $(157.09 \pm 4.18 \mathrm{ppm})$ and MESP $(134.04 \pm 10.30$ ppm). Conclusion: Oral ADSP and MESP that contain gallic acid possess acute and sub-acute antihypertensive effects in SHR, but MESP's effect was more prominent than ADSP.
\end{abstract}

Key words: Antihypertensive, Gallic acid, HPLC, Hypertension, Syzygium polyanthum.

Key Messages: This report highlights the acute 24-hr effect of oral Syzygium polyanthum leaves aqueous decoction and methanol extract on systolic blood pressure of conscious hypertensive rats. Interestingly, the reduction in blood pressure by oral Syzygium polyanthum leaves extracts was selective towards hypertensive rats. In addition, gallic acid was identified as the main phenolic compound in both extracts by HPLC analysis.

\section{INTRODUCTION}

Syzygium polyanthum (Wight) Walp or its synonym, Eugenia polyantha is a plant under Myrtaceae family. ${ }^{1}$ The leaf of this plant is commonly consumed as fresh salads and sometimes used as culinary additives in Malay cuisines. ${ }^{2}$ Malaysian folks usually consume the fresh young shoots or the mature leaf in its raw form or as a decoction for treating hypertension. Accordingly, few studies were embarked on verifying this traditional claim, this includes some in vivo and in vitro experimentations on normal and hypertensive rats. Our in vitro study has shown that the aqueous decoction (ADSP) and the methanol extract of S. polyanthum (MESP) leaves possessed significant vasorelaxation effects on isolated thoracic aorta rings of Wistar-Kyoto (WKY) and Spontaneously-Hypertensive (SHR) rats. ${ }^{3}$ This vasorelaxation effect is pos- sibly one of the underlying mechanisms responsible for antihypertensive activity by $S$. polyanthum leaves. Prior to that, our in vivo study has shown that both extracts significantly lowered the blood pressure of pentobarbital-anesthetized WKY and SHR when administered intravenously. ${ }^{2}$ In addition, recent in vivo studies have shown that sub-chronic daily oral treatment for 6-week with ultrasound-assisted methanol extract of $S$. polyanthum leaves significantly reduced the blood pressure ${ }^{4}$ and protected the kidney and aorta of SHR. ${ }^{4,5}$ Even though this later study may have addressed the sub-acute antihypertensive single-dose effect of oral S. polyanthum leaves was not yet being described. This acute study is specifically important for evaluating the sustenance and recovery ability of $S$. polyanthum leaves, but the acute $24-\mathrm{hr}$

Cite this article: Ismail A, Ramli NS, Mohamed M, Ahmad WANW. Acute and Sub-Acute Antihypertensive Effects of Syzygium polyanthumLeaf Extracts with Determination of Gallic Acid using HPLC Analysis. Pharmacog J. 2018;10(4):663-71. 
of blood pressure reduction upon a single-dose extract administration and this technique have been employed in other antihypertensive studies. ${ }^{6,7}$

In addition, the possible compound(s) that maybe responsible for such antihypertensive activity was not yet elucidated. Previous studies reported presence of some phytochemical groups such as tannins, flavonoids, glycosides, alkaloids, carbohydrates, steroids, triterpenoids and flavonoids in the crude macerated methanol extract of $S$. polyanthum leaves. ${ }^{89}$ Phenolic compounds such as caffeic acid and gallic acid ${ }^{10}$ and the triterpene squalene ${ }^{8,11}$ was detected in the crude methanol extract of S. polyanthum leaves. Among the identified compounds, gallic acid were previously shown to have some potentials with respect to antihypertensive action. Oral gallic acid was found to significantly reduce blood pressure of diabetic rats ${ }^{12}$ and to exhibit renin-inhibitory ${ }^{13}$ and vasorelaxation ${ }^{14,15}$ effects. However, none has identified the phytochemicals in aqueous decoction of this plant leaf as traditionally prepared.

In view of this, this study aims to examine the acute and sub-acute effects of oral ADSP on SBP of conscious WKY and SHR rats; and then to compare the effect with MESP; and lastly, to determine and quantify the amount of gallic acid in both extracts using high-performance-liquidchromatography (HPLC).

\section{MATERIALS AND METHODS}

\section{Chemicals}

Methanol, ferric chloride, formic acid, acetonitrile, gallic acid and sodium carboxymethylcellulose (CMC) were purchased from Merck, Germany. All chemicals were analytical grades. Losartan potassium (50 mg) was purchased from Abio Marketing Sdn. Bhd., Malaysia.

\section{Plant Materials}

S. polyanthum mature leaves $(1 \mathrm{~kg})$ were collected from District of Bachok, Kelantan, Malaysia in July 2013. The plant was authenticated by a botanist from Forest Research Institute Malaysia as Syzygium polyanthum (Wight) Walp var. Polyanthum. Dried leaves specimen was deposited into their herbarium (Sample number: PID-171011-10). S. polyanthum leaves were extracted using similar protocols as reported by Ismail et al. (2013). The aqueous decoction and methanolic extract of S. polyanthum leaves were designated as ADSP and MESP, respectively. The yield from $1 \mathrm{~kg}$ of fresh $S$. polyanthum leaves was 36.90 grams of ADSP and 6.20 grams of MESP. Both extracts were stored in $-20^{\circ} \mathrm{C}$ freezer until use.

\section{Preparation of Extracts and Drugs Solutions}

Stock solutions of ADSP and MESP $(100 \mathrm{mg} / \mathrm{ml})$ and losartan potassium $(5 \mathrm{mg} / \mathrm{ml})$ were prepared once every alternate day and was stored in a $4^{\circ} \mathrm{C}$ freezer. Basically, ADSP and losartan potassium were suspended in distilled water, but MESP was suspended in distilled water and added with pre-warmed $1.0 \%$ (w/v) sodium CMC. Sodium CMC was added to emulsify the highly viscous MESP with distilled water. Extracts and drug solutions were then homogenized using IKA Ultra-Turrax' T25 Basic homogenizer (IKA-Werke GmbH and Co., Darmstadt, Germany) at $24,000 \mathrm{rpm} / \mathrm{min}$ for $3 \mathrm{~min}$. From the stock solution, serial doses of ADSP and MESP from 2.00, 2.50 to $3.00 \mathrm{~g} / \mathrm{kg}$, and losartan potassium at a dose of $0.01 \mathrm{~g} / \mathrm{kg}$ solutions were daily prepared.

\section{Instrument Set-Up}

Rat tail cuff plethysmography blood pressure measuring system (IITC Life Science, California) with amplifier and an automatic cuff inflation was utilized. The amplifier was attached to a manual blood pressure scanner. The following recording parameters were employed: filter gain $=7$, pressure adjust $=3$, pulse gain $=8$, offset $=6$, maximum cuff pressure $=250 \mathrm{mmHg}$, deflation rate $=5.5 \mathrm{mmHg} / \mathrm{sec}$, and test termination $=2$ to determine rats' systolic blood pressure (SBP). The recordings were displayed using BPMonWin Monitor Version 1.35 (IITC Life Science, California). Only systolic blood pressure (SBP) was recorded since a light-based plethysmography only directly records the first pulse that appears when it re-enters the rat's tail artery during cuff deflation. ${ }^{16}$ This predicament may explain the scarcity of data on mean arterial and diastolic blood pressures in other studies with tail-cuff blood pressure measurement system. ${ }^{6,17-20}$

\section{Animals}

Male adult normotensive WKY and SHR rats at 3-month old, and with the weight range of 280 to $350 \mathrm{~g}$ were supplied by Animal Research and Service Centre, Health Campus, University Sains Malaysia (USM). The predilection of male rats over female rats was to avoid any potential impact of estrogen on study outcome since female rats' blood pressure can be affected by estrogen level. Estrogen may activate vasodilator pathway mediated by nitric oxide and prostacyclin, and also, it may inhibit vasoconstrictor pathway mediated by the sympathetic nervous system and angiotensin. ${ }^{21}$ The research methodology was approved by the Animal Ethics Committee, USM with approval number, USM/Animal Ethics Approval/2013/(89)(485). Rats were housed singleton in standard rat cages and were given standard rat pellet (Chipsi Classic Heimtierbett, Germany) and tap water ad libitum for 7 days. Room temperature was set at $24^{\circ} \mathrm{C}$ on a 12 -hr light-dark cycle. During this acclimatization period, a rat's physical restrainer tube (Size 81, IITC Inc. Life Science, California) without the nose and tail cap (uncapped) was placed permanently inside each housing cage to familiarize the rats with the restrainer tube before the experiment started. Since the restrainer is uncapped, the rats can move freely in and out of the restrainer.

\section{Animal Set-up}

Each rat was tenderly placed in rats physical restrainer (capped) and allowed to relax for 5 to $10 \mathrm{~min}$ and then placed into pre-warmed $\left(32^{\circ} \mathrm{C}\right)$ housing chamber. The tail of the restrained rat was carefully placed into the tail cuff equipped with photo sensor. The restrained rat (capped) could calm for another 5 to $10 \mathrm{~min}$ prior to measurement. The rat's SBP was measured once the rat has relaxed. The SBP recording was repeated until three most stable readings were obtained. These triplicate SBP values were then averaged.

\section{Acute Study: Effect of Single-Dose Treatment with ADSP and MESP on} Normotensive Wistar-Kyoto and Spontaneously Hypertensive Rats.

This study was designed to measure the magnitude of the blood pressure reduction and to evaluate its sustenance and recovery within $24 \mathrm{hrs}$ according to protocols described in a previous study. ${ }^{6}$ Thirty-six WKY rats were divided into 9 groups while 36 SHR rats were also divided into another 9 groups. Each group consisted of 4 rats. Group 1 received distilled water (vehicle to dissolve ADSP), thus serve as a negative control for ADSP-treated groups. Group 2 received distilled water plus $1 \%(\mathrm{w} / \mathrm{v})$ sodium CMC (vehicle for MESP), thus served as a negative control to MESP-treated groups. Group 3 received losartan potassium at a dose of $0.01 \mathrm{~g} / \mathrm{kg}$ to serve as a positive control in this study. Groups 4, 5 and 6 received ADSP at doses of $2.00,2.50$ and $3.00 \mathrm{~g} / \mathrm{kg}$, respectively while Groups 7, 8 and 9 received MESP at doses of 2.00, 2.50 and $3.00 \mathrm{~g} / \mathrm{kg}$, respectively.

A curved-feeding needle (18G, $2.25 \mathrm{~mm}$ tip, $50 \mathrm{~mm}$ length) was used for oral gavaging. SBP of rats was measured prior to each treatment and after $1,3,5,6$, and 24 hrs post-treatment according to protocols described by Ichimura et al. ${ }^{6}$ with a slight modification. This study recorded the SBP after $6 \mathrm{hrs}$ post-treatment, instead of $7 \mathrm{hrs}$ as outlined in protocols by Ichimura et al. ${ }^{6} \mathrm{SBP}$ recording was recorded after one hr post- 
treatment to allow for the natural process of digestion and absorption to take place. The next two-hr intervals at 3 and 5 hrs post-treatment was recorded to mimic the acute blood pressure measurement in human. Blood pressure was recorded after $6 \mathrm{hrs}$ post-treatment since the positive control drug (losartan potassium) used in this study manifested its effect after 6 hrs post-treatment. The final SBP recording after $24 \mathrm{hrs}$ of administration was utilized to monitor the recovery of rats upon treatment with the extracts or drug. After three stable recordings of SBP for each interval were obtained, the rats were immediately released from the restrained and then placed back inside the cage together with restrainer (uncapped). Rats can move freely in and out of the restrainer inside the cage with water and rats' pellet ad libitum until their next interval blood pressure measurement. After final SBP measurement, all rats were sacrificed using sodium pentobarbital at $100 \mathrm{mg} / \mathrm{kg}$ via intraperitoneal injection. The best dose for the extracts in reducing SBP was used for the next phase of study.

\section{Sub-Acute Study: Effect of Daily-Dose Administration of Extracts for 3-week in Spontaneously Hypertensive Rats.}

This study was conducted to determine the magnitude of effect upon daily-administration of extracts on blood pressure of SHR rats, and to observe the sustenance of blood pressure reduction by repeated administration and over time for a period of 3-week according to previous studies. ${ }^{19,20}$ SHR rats were divided into five groups wherein each group consisted of four rats. Group 1 received distilled water, Group 2 received distilled water plus $1 \%(\mathrm{w} / \mathrm{v})$ sodium CMC, Group 3 received losartan potassium ( $0.01 \mathrm{~g} / \mathrm{kg} /$ day), Group 4 received ADSP ( $2.5 \mathrm{~g} / \mathrm{kg} /$ day $)$, and Group 5 received MESP $(2.5 \mathrm{~g} / \mathrm{kg} /$ day $)$. Losartan which was selected as a standard reference drug for this study is a commercial anti-hypertensive drug, a prototype of angiotensin type II receptor blockers group with proven antihypertensive efficacy and less-side effect profile. ${ }^{22}$ The specific dose of $2.5 \mathrm{~g} / \mathrm{kg} /$ day was chosen based on significant finding for this dose during our acute, single-dose effect study. SBP was recorded before treatment and was denoted as measurement at week 0. Gavaging was performed from 10 a.m. to 12 noon daily to avoid blood pressure variability induced by circadian rhythm. ${ }^{23}$ SBP was then measured weekly at day 8 (week 1), day 15 (week 2), and day 22 (week 3). After final SBP measurement on day 22 (week 3), all rats were sacrificed using sodium pentobarbital at a terminal anaesthesia dose of $100 \mathrm{mg} / \mathrm{kg}$ via intraperitoneal injection.

\section{Qualitative Screening for Phenolics using Ferric Chloride Test}

Phenolic compound screening in ADSP and MESP was performed using ferric chloride test according to protocols described by Raaman. ${ }^{24}$ Briefly, $50 \mathrm{mg}$ of ADSP was dissolved in $5 \mathrm{ml}$ of distilled water, while $50 \mathrm{mg}$ of MESP was dissolved in $5 \mathrm{ml}$ of $95.0 \%$ (v/v) methanol. These solutions were then added with two drops of neutral $5.0 \%(\mathrm{w} / \mathrm{v})$ ferric chloride. In each test, distilled water and $95.0 \%(\mathrm{v} / \mathrm{v})$ methanol were utilised as negative controls. Any colour changes of extracts and negative control solutions were observed as any appearance of intense green, purple, blue-black colours would indicate for the presence of phenols. ${ }^{25}$

\section{Gallic Acid Quantification using High Performance Liquid Chromatography}

The phenolic compound in both extracts were identified using (HPLC) analysis. Ten mg of ADSP and MESP were dissolved in $1 \mathrm{ml}$ methanol and the resulting solutions were filtered prior to analysis. ADSP and MESP were analysed using a HPLC system (Waters Delta 600 with 600 Controller) with photodiode array detector (Waters 996). A phenomenex-Luna $(5 \mu \mathrm{m})$ column was used $(4.6 \mathrm{~mm}$ i.d x $250 \mathrm{~mm})$ as stationary phase, and for gradient elution of the constituents, two solvents denoted as "A" and "B" were employed. Solvent "A" was $0.1 \%$ aqueous formic acid, while solvent " $\mathrm{B}$ " was acetonitrile. The gradient elution sys- tem used in this study was set according to Table 1 . The flow rate was set at $1 \mathrm{ml} / \mathrm{min}$ with the injection volume of $10 \mu \mathrm{l}$. The major peaks were analysed at different wavelengths of 210, 254, 280 and $300 \mathrm{~nm}$ in terms of their retention times and the peak areas. In the subsequent test, gallic acid (100 ppm) was run as a standard together with ADSP and MESP, and then analysed at a specific wavelength of $280 \mathrm{~nm}$. For gallic acid quantification, gallic acid with serial concentrations of 40,60,80, 100, 120 , and $140 \mathrm{ppm}$ were run. A standard curve of gallic acid was plotted where the $\mathrm{y}$-axis represents the absorbance while the $\mathrm{x}$-axis represents the concentration of the gallic acid (ppm). The concentrations of gallic acid in ADSP and MESP were then calculated based on the peak areas of ADSP and MESP in the chromatograms and the linear equation derived from the standard curve.

\section{Statistical Analysis}

Data was expressed as mean \pm standard error of mean (S.E.M). Statistical analyses were performed using Graph Pad' PRISM Version 6 (Graph Pad, San Diego, CA, USA). Unpaired t-test was used to compare the mean SBP between WKY and SHR rats. Two-way ANOVA was carried out to determine the overall effects, and then followed by post-hoc Bonferroni for multiple comparisons. All the tests were two-tailed and the value of $\mathrm{P}$ less than $0.05(P<0.05)$ was considered as statistically significant.

\section{RESULTS}

\section{Acute Study: Effect of Single-Dose Treatment with Extracts on} Normotensive Wistar-Kyoto and Spontaneously Hypertensive Rats.

The mean SBP of WKY and SHR rats used in this study were $153.07 \pm$ $1.02(n=36)$ and $182.42 \pm 0.98 \mathrm{mmHg}(n=36)$, respectively. The mean baseline SBP of WKY rats $(\mathrm{n}=36)$ was significantly lower than the mean SBP of SHR rats $(P<0.001)(\mathrm{n}=36)$.

Time-course changes in the mean SBP of normotensive WKY rats $(n=4)$ before and after receiving their respective treatments are shown in Table 2. There was no significant difference between the means SBP of the two negative control groups (the distilled water- and the distilled water plus sodium CMC-treated groups) in WKY rats at any specified time intervals used in this study. The mean SBP for all WKY-treated groups were not significantly different than their pre-treatment baseline values at any specified time intervals except for losartan $(0.01 \mathrm{~g} / \mathrm{kg})$-treated group after $6 \mathrm{hrs}$ of its administration $(P<0.001)$. The SBP reduction in losartan-treated group at this point of time $(\mathrm{t}=6)$ was significantly different $(P<0.001)$ as compared to the mean SBP of the negative control-treated group. The mean SBP was fully recovered in losartan-treated groups after $24 \mathrm{hrs}$ of treatment administration.

Table 3 shows time-course changes in mean SBP of SHR rats before and after receiving their respective treatments. Similarly, there was no significant difference between the mean SBP of the two negative control groups (the distilled water- and the distilled water plus sodium CMCtreated groups) in SHR rats at any specified time intervals used in this study. The mean SBP for losartan $(0.01 \mathrm{~g} / \mathrm{kg})$-treated group after $6 \mathrm{hrs}$ of

Table 1: Composition of mobile phase for elution of constituents.

\begin{tabular}{cccc}
\hline Time $(\mathrm{min})$ & Flow rate $(\mathrm{ml} / \mathrm{min})$ & $\% \mathrm{~A}$ & $\% \mathrm{~B}$ \\
\hline 0.00 & 1.0 & 85 & 15 \\
12.00 & 1.0 & 75 & 25 \\
22.00 & 1.0 & 75 & 25 \\
25.00 & 1.0 & 85 & 15 \\
35.00 & 1.0 & 85 & 15 \\
\hline
\end{tabular}

Note: A: $0.1 \%$ aqueous formic acid, and B: acetonitrile. 
Ismail, et al:: Acute and Sub-Acute Antihypertensive Effects of Syzygium polyanthum Leaf Extracts

Table 2: Time-course changes in SBP of WKY rats $(n=4)$ treated with vehicle, losartan potassium $(0.01 \mathrm{~g} / \mathrm{kg})$, and increasing doses of ADSP or MESP $(2.00,2.50$ and $3.00 \mathrm{~g} / \mathrm{kg})$ at specified time intervals within $24 \mathrm{hrs}$.

\begin{tabular}{|c|c|c|c|c|c|c|}
\hline \multirow{3}{*}{ Group } & \multicolumn{6}{|c|}{ Systolic Blood Pressures of WKY Rats at Specific Time (hours) } \\
\hline & $\mathrm{t}=0 \mathrm{hr}$ & $\mathrm{t}=1 \mathrm{hr}$ & $t=3 \mathrm{hrs}$ & $t=5 \mathrm{hrs}$ & $t=6 \mathrm{hrs}$ & $t=24 \mathrm{hrs}$ \\
\hline & $\begin{array}{l}\text { Initial SBP in } \\
\qquad \mathrm{mmHg}\end{array}$ & $\begin{array}{l}\text { SBP in } \mathrm{mmHg} \\
\text { [\% changes] }\end{array}$ & $\begin{array}{c}\mathrm{SBP} \text { in } \mathrm{mmHg} \\
\text { [\% changes] }\end{array}$ & $\begin{array}{c}\text { SBP in } \mathrm{mmHg} \\
\text { [\% changes] }\end{array}$ & $\begin{array}{l}\mathrm{SBP} \text { in } \mathrm{mmHg} \\
\text { [\% changes] }\end{array}$ & $\begin{array}{c}\text { SBP in } \mathrm{mmHg} \\
{[\% \text { changes] }}\end{array}$ \\
\hline $\begin{array}{c}\text { Distilled water } \\
\text { (Negative control for ADSP-and } \\
\text { losartan-treated groups) }\end{array}$ & $156.00 \pm 1.04$ & $\begin{array}{l}154.50 \pm 2.75 \\
{[1.14 \pm 1.04]}\end{array}$ & $\begin{array}{l}163.67 \pm 2.52 \\
{[-4.21 \pm 1.21]}\end{array}$ & $\begin{array}{l}151.17 \pm 3.88 \\
{[1.82 \pm 1.89]}\end{array}$ & $\begin{array}{l}148.00 \pm 6.03 \\
{[4.29 \pm 2.50]}\end{array}$ & $\begin{array}{l}149.22 \pm 4.92 \\
{[5.80 \pm 2.43]}\end{array}$ \\
\hline $\begin{array}{c}\text { Distilled water }+ \\
1 \% \text { sodium CMC } \\
\text { (Negative control for MESP- } \\
\text { treated groups) }\end{array}$ & $152.50 \pm 0.87$ & $\begin{array}{l}154.25 \pm 0.95 \\
{[1.15 \pm 0.16]}\end{array}$ & $\begin{array}{l}153.46 \pm 1.34 \\
{[-0.63 \pm 0.57]}\end{array}$ & $\begin{array}{l}151.25 \pm 0.75 \\
{[0.80 \pm 1.03]}\end{array}$ & $\begin{array}{l}154.17 \pm 1.04 \\
{[-1.09 \pm 0.38]}\end{array}$ & $\begin{array}{l}154.75 \pm 1.45 \\
{[-1.48 \pm 0.81]}\end{array}$ \\
\hline $\begin{array}{c}\text { Losartan potassium, } \\
0.01 \mathrm{~g} / \mathrm{kg} \text { (Positive control) }\end{array}$ & $150.39 \pm 2.84$ & $\begin{array}{l}145.33 \pm 2.03 \\
{[3.27 \pm 2.80]}\end{array}$ & $\begin{array}{l}148.22 \pm 2.75 \\
{[1.32 \pm 3.37]}\end{array}$ & $\begin{array}{l}147.56 \pm 3.76 \\
{[1.72 \pm 4.32]}\end{array}$ & $\begin{array}{c}133.72 \pm 5.611^{* * * \delta} \\
{[11.03 \pm 3.99]^{\star * \gamma}}\end{array}$ & $\begin{array}{l}158.94 \pm 3.72 \\
{[-5.85 \pm 4.38]}\end{array}$ \\
\hline ADSP, $2.00 \mathrm{~g} / \mathrm{kg}$ & $152.08 \pm 4.49$ & $\begin{array}{l}154.08 \pm 4.45 \\
{[-2.28 \pm 4.18]}\end{array}$ & $\begin{array}{l}153.50 \pm 2.57 \\
{[-1.26 \pm 4.05]}\end{array}$ & $\begin{array}{l}154.75 \pm 1.49 \\
{[-2.08 \pm 3.81]}\end{array}$ & $\begin{array}{l}151.88 \pm 2.29^{b} \\
{[-0.02 \pm 1.93]^{a}}\end{array}$ & $\begin{array}{l}150.50 \pm 4.52 \\
{[0.99 \pm 1.94]}\end{array}$ \\
\hline ADSP, $2.50 \mathrm{~g} / \mathrm{kg}$ & $154.75 \pm 3.17$ & $\begin{array}{l}158.83 \pm 1.88 \\
{[-1.13 \pm 3.76]}\end{array}$ & $\begin{array}{c}153.00 \pm 2.07 \\
{[0.94 \pm 3.19]}\end{array}$ & $\begin{array}{l}158.00 \pm 0.79 \\
{[-2.22 \pm 1.98]}\end{array}$ & $\begin{array}{l}154.58 \pm 4.64^{\mathrm{c}} \\
{[0.15 \pm 1.51]^{\mathrm{a}}}\end{array}$ & $\begin{array}{l}152.04 \pm 2.44 \\
{[1.69 \pm 1.52]}\end{array}$ \\
\hline ADSP, $3.00 \mathrm{~g} / \mathrm{kg}$ & $157.46 \pm 1.11$ & $\begin{array}{l}151.75 \pm 4.25 \\
{[3.64 \pm 2.47]}\end{array}$ & $\begin{array}{c}153.29 \pm 1.90 \\
{[2.64 \pm 1.04]}\end{array}$ & $\begin{array}{l}156.25 \pm 1.70 \\
{[0.76 \pm 1.22]}\end{array}$ & $\begin{array}{c}155.29 \pm 1.40^{c} \\
{[1.37 \pm 0.90]}\end{array}$ & $\begin{array}{l}156.25 \pm 0.85 \\
{[0.76 \pm 0.62]}\end{array}$ \\
\hline MESP, $2.00 \mathrm{~g} / \mathrm{kg}$ & $161.50 \pm 2.40$ & $\begin{array}{l}151.50 \pm 1.21 \\
{[6.12 \pm 1.81]}\end{array}$ & $\begin{array}{l}151.13 \pm 1.21 \\
{[6.39 \pm 1.00]}\end{array}$ & $\begin{array}{l}157.96 \pm 3.60 \\
{[2.04 \pm 3.55]}\end{array}$ & $\begin{array}{c}154.38 \pm 1.57^{\mathrm{c}} \\
{[4.34 \pm 1.95]}\end{array}$ & $\begin{array}{l}159.38 \pm 2.01 \\
{[1.28 \pm 1.42]}\end{array}$ \\
\hline MESP, $2.50 \mathrm{~g} / \mathrm{kg}$ & $158.75 \pm 5.42$ & $\begin{array}{l}158.83 \pm 1.24 \\
{[0.39 \pm 3.34]}\end{array}$ & $\begin{array}{l}157.42 \pm 1.64 \\
{[0.53 \pm 3.19]}\end{array}$ & $\begin{array}{l}154.38 \pm 1.28 \\
{[2.51 \pm 2.44]}\end{array}$ & $\begin{array}{l}153.13 \pm 2.70^{c} \\
[3.35 \pm 2.21)]\end{array}$ & $\begin{array}{l}156.04 \pm 3.32 \\
{[1.57 \pm 1.59]}\end{array}$ \\
\hline MESP, $3.00 \mathrm{~g} / \mathrm{kg}$ & $156.29 \pm 0.83$ & $\begin{array}{c}153.63 \pm 2.49 \\
{[-1.72 \pm 1.16]}\end{array}$ & $\begin{array}{c}155.67 \pm 2.81 \\
{[0.41 \pm 1.47]}\end{array}$ & $\begin{array}{c}152.75 \pm 3.68 \\
{[2.28 \pm 2.04]}\end{array}$ & $\begin{array}{c}152.88 \pm 3.60^{c} \\
{[2.19 \pm 2.23]}\end{array}$ & $\begin{array}{c}151.67 \pm 1.69 \\
{[2.96 \pm 0.90]}\end{array}$ \\
\hline
\end{tabular}

Note: Results were expressed as mean \pm S.E.M. “-” sign: Increment, ADSP: Aqueous decoction of S. polyanthum leaves, MESP: Methanolic extract of S. polyanthum leaves, mmHg: Millimetres mercury, SBP: Systolic blood pressure,\% Changes: Percent changes from pre-treatment mean SBP values,g/kg: Gram per kilogram,WKY: Wistar-Kyoto rats. ${ }^{* *}: P<0.01$ and ${ }^{* *}: P<0.001$, all $v s$. pre-treatment baseline mean SBP $(\mathrm{t}=0) . \gamma: P<0.01$ and $\delta: P<0.001$, all $v s$. mean SBP value for negative control group at the same time interval. a: $P<0.05$, b: $P<0.01$ and c: $P<0.001$, all $v s$. mean SBP value for positive control group at the same time interval.

administration was significantly different $(P<0.001)$ compared to its pretreatment baseline value. Its SBP reduction at this point of time $(\mathrm{t}=6)$ was significantly different $(P<0.001)$ as compared to the SBP change for the negative control-treated group.

Other than losartan, both extracts also showed significant reductions in SBP at certain point of time intervals as indicated in Table 3. Specifically, the mean SBP in ADSP $(2.50 \mathrm{~g} / \mathrm{kg})$ - and ADSP $(3.00 \mathrm{~g} / \mathrm{kg})$ - treated groups were significantly different than their pre-treatment baseline values at various post-treatment times as depicted in Table 3. However, only SBP reductions by ADSP $(3.00 \mathrm{~g} / \mathrm{kg})$ after $1(P<0.05), 3(P<0.01), 5$ $(P<0.05)$ and $6(P<0.05)$ hrs of administration were significantly different in comparison to the mean SBP change in the negative control-treated group (Table 3). In terms of the trend of SBP reduction, the effects by $\operatorname{ADSP}(3.00 \mathrm{~g} / \mathrm{kg})$ were observed as early as after $1 \mathrm{hr}$ of administration, and the maximum effect was achieved and then remained plateau within 3 to $5 \mathrm{hrs}$ of administration and then started to recover after $6 \mathrm{hrs}$ of administration. The mean SBP in this group was fully recovered after 24 hrs of treatment administration.

The mean SBP for SHR groups, treated with MESP at the doses of 2.00 $\mathrm{g} / \mathrm{kg}, 2.50 \mathrm{~g} / \mathrm{kg}$ and $3.00 \mathrm{~g} / \mathrm{kg}$ were significantly different than their pretreatment baseline values at various post-treatment times (Table 3). In comparison with the mean SBP change for the negative control-treated group at each post-treatment times, the mean SBP reductions by MESP at the dose of $2.00 \mathrm{~g} / \mathrm{kg}$ were significantly different $(P<0.001)$ after $3 \mathrm{hrs}$ of extract administration, whereby the mean SBP reductions by MESP at the dose of $2.50 \mathrm{~g} / \mathrm{kg}$ were significantly different after $1(P<0.01), 3$ $(P<0.01), 5(P<0.001)$ and $6(P<0.001)$ hrs of extract administration, and finally the SBP reductions by MESP at the highest dose of $3.00 \mathrm{~g} /$ $\mathrm{kg}$ were significantly different after $3(P<0.001)$ and $5(P<0.01)$ hrs after extract administration. The SBP reduction by MESP in SHR rats was not dose-dependent since the maximum mean SBP reduction by MESP was achieved at the dose of $2.50 \mathrm{~g} / \mathrm{kg}$ by $36.17 \pm 6.12 \mathrm{mmHg}$, which equals to $20.08 \pm 3.53 \%$ reduction; and then, at the dose of $3.00 \mathrm{~g} / \mathrm{kg}$ by 19.08 $\pm 1.40 \mathrm{mmHg}$, which equals to $9.96 \pm 0.70 \%$ reduction; while the least reduction was observed at the dose of $2.00 \mathrm{~g} / \mathrm{kg}$ by $11.08 \pm 0.63 \mathrm{mmHg}$, which equals to $6.23 \pm 0.36 \%$ reduction. All these SBP reductions by MESP-treated groups were fully recovered after $24 \mathrm{hrs}$ of administration. It is also important to note that the mean SBP reduction by MESP at the dose of $2.50 \mathrm{~g} / \mathrm{kg}(36.17 \pm 6.12 \mathrm{mmHg}$, which equals to $20.08 \pm$ $3.53 \%$ reduction) was significantly higher $(P<0.01)$ than the mean SBP reduction by losartan $(17.92 \pm 4.80 \mathrm{mmHg}$, which equals to $9.90 \pm 2.78$ $\%$ reduction) after $6 \mathrm{hrs}$ of administration.

Other than that, Table 3 also shows comparison between the two extracts at the same dose and at the same time interval. It was observed that the mean SBP reduction by MESP $(36.17 \pm 6.12 \mathrm{mmHg}$, which equals to $20.08 \pm 3.53 \%$ reduction $)$ was significantly higher $(P<0.01)$ than the SBP 
Table 3: Time-course changes in SBP of SHR rats $(n=4)$ treated with vehicle, losartan potassium $(0.01 \mathrm{~g} / \mathrm{kg})$, and increasing doses of ADSP or MESP $(2.00,2.50$ and $3.00 \mathrm{~g} / \mathrm{kg})$ at specified time intervals within $24 \mathrm{~h}$.

\begin{tabular}{|c|c|c|c|c|c|c|c|c|c|c|}
\hline \multirow[b]{3}{*}{ No } & \multirow{3}{*}{ Group } & \multicolumn{9}{|c|}{ Systolic Blood Pressures of SHR Rats at Specific Time (hours) } \\
\hline & & $\mathrm{t}=0 \mathrm{hr}$ & $\mathrm{t}=1 \mathrm{hr}$ & $t=3 \mathrm{hrs}$ & & $t=5 \mathrm{hrs}$ & & $\mathrm{t}=6 \mathrm{hrs}$ & & $\mathrm{t}=24 \mathrm{hrs}$ \\
\hline & & $\begin{array}{l}\text { Initial SBP in } \\
\mathrm{mmHg}\end{array}$ & $\begin{array}{l}\text { SBP in } \mathrm{mmHg} \\
\text { [\% changes] }\end{array}$ & $\begin{array}{c}\text { SBP in } \mathrm{mmHg} \\
\text { [\% changes] }\end{array}$ & & $\begin{array}{l}\text { SBP in } \mathrm{mmH} \\
{[\% \text { changes }}\end{array}$ & $\begin{array}{l}\mathrm{Hg} \\
\text { es] }\end{array}$ & $\begin{array}{l}\text { SBP in } \mathrm{mmHg} \\
\text { [\% changes] }\end{array}$ & & $\begin{array}{l}\text { SBP in } \mathrm{mmHg} \\
\text { [\% changes] }\end{array}$ \\
\hline 1. & $\begin{array}{l}\text { Distilled water } \\
\text { (Negative control } \\
\text { for ADSP-and } \\
\text { losartan-treated } \\
\text { groups) }\end{array}$ & $179.33 \pm 1.81$ & $\begin{array}{l}178.17 \pm 4.43 \\
{[0.65 \pm 2.20]}\end{array}$ & $\begin{array}{l}174.96 \pm 7.81 \\
{[2.45 \pm 4.17]}\end{array}$ & & $\begin{array}{l}173.50 \pm 4.46 \\
{[3.28 \pm 1.92]}\end{array}$ & & $\begin{array}{l}172.04 \pm 2.67 \\
{[4.04 \pm 1.65]}\end{array}$ & & $\begin{array}{l}179.33 \pm 4.68 \\
{[0.01 \pm 2.29]}\end{array}$ \\
\hline 2. & $\begin{array}{c}\text { Distilled water + } \\
1 \% \text { sodium CMC } \\
\text { (Negative control } \\
\text { for MESP-treated } \\
\text { groups) }\end{array}$ & $188.92 \pm 2.23$ & $\begin{array}{l}189.54 \pm 1.28 \\
{[-0.36 \pm 1.05]}\end{array}$ & $\begin{array}{l}191.42 \pm 2.16 \\
{[-1.33 \pm 0.19]}\end{array}$ & & $\begin{array}{l}186.42 \pm 2.12 \\
{[1.32 \pm 0.42]}\end{array}$ & & $\begin{array}{l}183.50 \pm 2.25 \\
{[2.85 \pm 1.07]}\end{array}$ & & $\begin{array}{l}185.71 \pm 1.84 \\
{[1.67 \pm 1.24]}\end{array}$ \\
\hline 3. & $\begin{array}{c}\text { Losartan } \\
\text { potassium, } \\
0.01 \mathrm{~g} / \mathrm{kg} \\
\text { (Positive control) }\end{array}$ & $181.83 \pm 3.91$ & $\begin{array}{l}178.38 \pm 3.02 \\
{[1.85 \pm 1.31]}\end{array}$ & $\begin{array}{l}177.96 \pm 4.94 \\
{[2.16 \pm 0.98]}\end{array}$ & & $\begin{array}{l}171.83 \pm 5.53 \\
{[5.46 \pm 2.77]}\end{array}$ & & $\begin{array}{l}163.92 \pm 6.80 * * * x \\
{[9.90 \pm 2.78]^{* * \gamma}}\end{array}$ & & $\begin{array}{r}177.88 \pm 5.08 \\
{[2.22 \pm 0.82]}\end{array}$ \\
\hline 4. & $\begin{array}{c}\text { ADSP, } \\
2.00 \mathrm{~g} / \mathrm{kg}\end{array}$ & $183.50 \pm 4.56$ & $\begin{array}{l}183.88 \pm 4.51 \\
{[-0.22 \pm 0.79]}\end{array}$ & $\begin{array}{l}186.00 \pm 3.94 \\
{[-1.41 \pm 1.11]}\end{array}$ & & $\begin{array}{l}184.96 \pm 3.19 \\
{[-0.87 \pm 1.26]}\end{array}$ & & $\begin{array}{l}182.46 \pm 3.58^{\mathrm{a}} \\
{[0.50 \pm 1.39]}\end{array}$ & & $\begin{array}{l}184.13 \pm 2.20 \\
{[-0.44 \pm 1.43]}\end{array}$ \\
\hline 5. & $\begin{array}{c}\text { ADSP, } \\
2.50 \mathrm{~g} / \mathrm{kg}\end{array}$ & $189.42 \pm 3.15$ & $\begin{array}{l}180.71 \pm 3.01 \\
{[4.59 \pm 0.82]}\end{array}$ & $\begin{array}{l}174.67 \pm 7.50 * \\
{[7.90 \pm 2.67]}\end{array}$ & & $\begin{array}{l}172.83 \pm 7.68 * \\
{[8.84 \pm 3.07]}\end{array}$ & $\begin{array}{l}* * \\
* *\end{array}$ & $\begin{array}{l}179.42 \pm 3.19^{\mathrm{a}} \\
{[5.15 \pm 2.90]}\end{array}$ & & $\begin{array}{l}188.50 \pm 2.47 \\
{[0.46 \pm 0.76]}\end{array}$ \\
\hline 6. & $\begin{array}{l}\text { ADSP, } \\
3.00 \mathrm{~g} / \mathrm{kg}\end{array}$ & $190.50 \pm 1.66$ & $\begin{array}{l}175.71 \pm 4.85^{*} \\
{[7.77 \pm 2.36]^{\star x}}\end{array}$ & $\begin{array}{l}167.79 \pm 2.75^{\star *} \\
{[11.92 \pm 1.31]^{\star * \gamma b}}\end{array}$ & $\neq$ & $\begin{array}{l}168.50 \pm 3.35 * \\
{[11.51 \pm 2.24]}\end{array}$ & $\begin{array}{l}* * * \\
* * * x\end{array}$ & $\begin{array}{l}169.25 \pm 3.27^{\star * *} \\
{[11.16 \pm 1.39]^{\star * *} x}\end{array}$ & $=$ & $\begin{array}{l}190.88 \pm 0.92 \\
{[-0.22 \pm 0.85]}\end{array}$ \\
\hline 7. & $\begin{array}{l}\text { MESP, } \\
2.00 \mathrm{~g} / \mathrm{kg}\end{array}$ & $178.00 \pm 2.70$ & $\begin{array}{l}174.63 \pm 4.01 \\
{[1.86 \pm 2.20]}\end{array}$ & $\begin{array}{l}166.92 \pm 2.73 * \delta \\
{[6.23 \pm 0.36] * \gamma}\end{array}$ & & $\begin{array}{l}167.75 \pm 1.93 * \\
[5.73 \pm 0.92)] *\end{array}$ & $\begin{array}{l}* x \\
*\end{array}$ & $\begin{array}{l}171.75 \pm 1.11 \\
{[3.47 \pm 1.09]}\end{array}$ & & $\begin{array}{l}178.29 \pm 3.46 \\
{[-0.25 \pm 2.78]}\end{array}$ \\
\hline 8. & $\begin{array}{c}\text { MESP, } \\
2.50 \mathrm{~g} / \mathrm{kg}\end{array}$ & $180.63 \pm 2.49$ & $\begin{array}{l}163.54 \pm 6.71^{* * * \delta} \\
{[9.55 \pm 2.60]^{* * * \gamma}}\end{array}$ & $\begin{array}{l}164.92 \pm 5.18^{\star * * \delta} \\
{[8.74 \pm 2.01]^{* * * \gamma}}\end{array}$ & & $\begin{array}{l}156.88 \pm 1.90 * \\
{[13.12 \pm 1.19]}\end{array}$ & $\begin{array}{l}* * * \delta \\
* * * \delta \mathrm{b}\end{array}$ & $\begin{array}{l}144.46 \pm 7.35^{* * * \delta \mathrm{a}} \\
{[20.08 \pm 3.53]^{* * * \delta \mathrm{b}}}\end{array}$ & & $\begin{array}{l}180.00 \pm 3.11 \\
{[0.36 \pm 0.57]}\end{array}$ \\
\hline 9. & $\begin{array}{c}\text { MESP, } \\
3.00 \mathrm{~g} / \mathrm{kg}\end{array}$ & $191.50 \pm 0.61$ & $\begin{array}{l}183.38 \pm 5.60 \\
{[5.14 \pm 2.77]}\end{array}$ & $\begin{array}{l}172.42 \pm 1.05^{\star * * \delta} \\
{[9.96 \pm 0.70]^{\star * * \delta}}\end{array}$ & & $\begin{array}{l}175.33 \pm 1.41 \text { * } \\
{[8.44 \pm 0.80] \text { * }}\end{array}$ & $\begin{array}{l}* * * \\
* * * y\end{array}$ & $\begin{array}{l}173.75 \pm 2.78^{\star * *} \\
{[9.26 \pm 1.57]^{* * *}}\end{array}$ & & $\begin{array}{l}192.25 \pm 1.05 \\
{[-0.39 \pm 0.48]}\end{array}$ \\
\hline
\end{tabular}

Note: Results were expressed as mean \pm S.E.M. “-” sign: Increment, ADSP: Aqueous decoction of S. polyanthum leaves, MESP: Methanolic extract of S. polyanthum leaves, mmHg: Millimetres mercury, SBP: Systolic blood pressure, \% Changes: Percent changes from pre-treatment mean SBP values, g/kg: Gram per kilogram, SHR: Spontaneously Hypertensive rats. ${ }^{*}: P<0.05,{ }^{* *}: \mathrm{P}<0.01$ and ${ }^{* * *}: P<0.001$, all vs. pre-treatment baseline mean $\operatorname{SBP}(\mathrm{t}=0) . \chi: P<0.05, \gamma: P<0.01$ and $\delta: P<0.001$, all vs. mean SBP value for negative control group at the same time interval. a: $\mathrm{P}<0.05, \mathrm{~b}: \mathrm{P}<0.01$ and $\mathrm{c}: \mathrm{P}<0.001$, all vs. mean $\mathrm{SBP}$ value for positive control group at the same time interval. $\neq: P<0.05$ and \#: $P<0.001$, mean SBP values for ADSP- vs. mean SBP value for MESP-treated group at the same dose and at the same time interval.

reduction by ADSP at the same dose of $2.50 \mathrm{~g} / \mathrm{kg}(10.00 \pm 5.54 \mathrm{mmHg}$, which equals to $5.15 \pm 2.90 \%$ reduction) after $6 \mathrm{hrs}$ of extract administration.

\section{Sub-Acute Study: Effect of Daily Treatment with ADSP and MESP on Spontaneously Hypertensive Rats for 3-Week.}

In this study, the mean SBP of SHR rats was $183.46 \pm 1.12 \mathrm{mmHg}(\mathrm{n}=20)$. Experiment on WKY rats was omitted in this phase of study since our acute, single-dose effect study had shown that both extracts did not cause any significant changes in SBP of WKY rats (Table 2). Figure 1 shows the weekly, time-course SBP changes in SHR rats during 3-week treatment period. Daily treatment with both vehicles that served as negative controls for 3-week did not cause any significant reduction in SBP of SHR rats as compared to pre-treatment SBP value (Figure 1). Daily treatment with positive control drug, losartan potassium $(0.01 \mathrm{~g} / \mathrm{kg} /$ day $)$ significantly reduced the SBP of SHR rats after 2 -week by $13.96 \pm 3.45 \mathrm{mmHg}$ $(8.37 \pm 1.51 \%)(P<0.001)$, and then after 3 -week, the SBP reduction was found to be at $12.75 \pm 2.98 \mathrm{mmHg}(6.87 \pm 1.64 \%)(P<0.001)$ (Figure 1). There was no significant difference between the effects after 2 -week with the effect after 3-week (Figure 1).

For extract-treated group, the SBPs of SHR rats that received daily treatment with ADSP $(2.50 \mathrm{~g} / \mathrm{kg} /$ day $)$ were significantly reduced only after 3 -week by $8.63 \pm 4.07 \mathrm{mmHg}(4.59 \pm 2.18 \%)(P<0.05)$ (Figure 1$)$. On the other hand, daily treatment with MESP (2.50 g/kg/day) showed faster response, whereby the SBP of SHR rats was significantly reduced after 2 -week by $15.25 \pm 4.36 \mathrm{mmHg}(8.29 \pm 2.25 \%)(P<0.001)$ and the effect was sustained after 3 -week at $16.46 \pm 3.52 \mathrm{mmHg}(8.95 \pm 1.84 \%)$ 
$(P<0.001)$ (Figure 1). Like losartan, there was no significant difference between the effects measured after 2-week with the 3-week (Figure 1).

This study also showed that the SBP reductions by MESP $(2.50 \mathrm{~g} / \mathrm{kg} / \mathrm{day})$ were always significantly higher than $\operatorname{ADSP}(2.50 \mathrm{~g} / \mathrm{kg} /$ day $)$ after 2 -week $(P<0.05)$ and 3 -week $(P<0.05)$ treatment. Apart from that, the measured SBP reductions by MESP were similar with the effects shown by the positive control drug, losartan potassium $(0.01 \mathrm{~g} / \mathrm{kg} /$ day $)$ after 2 -week and after 3-week of treatment (Figure 1).

\section{Qualitative Screening for Phenolics using Ferric Chloride Test}

Phenolics were detected in both ADSP and MESP as indicated by the appearance of intense blue-black colouration of the mixture upon addition with ferric chloride. No colour changes were observed for negative control solutions.

\section{Gallic Acid Quantification in ADSP and MESP using High Performance Liquid Chromatography}

HPLC chromatograms of ADSP (Figure 2) and MESP (Figure 3) show the presence of multiple peaks which were detected at wavelengths of 210, 254, 280 and $300 \mathrm{~nm}$. It was noted that there was one major peak (indicated by the highest peak in the HPLC chromatogram) in ADSP which was eluted with retention time of 4.068, 4.072, 4.073, and 4.073 at the wavelengths of $210 \mathrm{~nm}, 254 \mathrm{~nm}, 280 \mathrm{~nm}$, and $300 \mathrm{~nm}$, respectively (Figure 2). Like ADSP, there was one major peak identified in MESP chromatogram which was eluted with retention time of 4.068, 4.071, 4.072 , and 4.072 at the wavelength of $210 \mathrm{~nm}, 254 \mathrm{~nm}, 280 \mathrm{~nm}$ and 300 $\mathrm{nm}$, respectively (Figure 3 ). This major compound was identified as gallic acid as the HPLC analysis on both extracts at specific wavelength of $280 \mathrm{~nm}$ had shown similar retention time with gallic acid which was used as a reference compound (Figure 4). The standard calibration curve for gallic acid is shown in Figure 5. The calibrated equation obtained from the gallic acid standard curve is $y=38590 x-240357\left(R^{2}=0.9992\right)$. Based on the peak areas on the chromatogram and the standard curve of gallic acid, the concentrations of gallic acid in ADSP and MESP are presented in Table 4.

\section{DISCUSSION}

Our acute study has shown that both oral aqueous decoction (ADSP) and methanol extract (MESP) of S. polyanthum leaves caused significant reductions in SBP of SHR rats, observed between the first to six hr post-administration with complete recovery achieved after 24-hr. Another notable finding was that the reduction in blood pressure by oral ADSP and MESP occurred only in spontaneously hypertensive rats (SHR), a model that mimics essential hypertension in human, but not on the normotensive Wistar-Kyoto (WKY) rat. This finding is vital for our understanding since $S$. polyanthum leaves were not only consumed as a remedy for hypertension, but they are also regularly being consumed as a culinary additive in many Malay cuisines and even consumed in its raw form as a salad.
In fact, the selective reduction in blood pressure was previously observed in studies on quercetin ${ }^{26}$ and captopril. ${ }^{27}$ Quercetin reduced the blood pressure of SHR rats by restoring the nitric oxide-induced vasorelaxation and by reducing the production of vasoconstrictor isoprostane $F_{2 a}$, a marker for oxidative stress. ${ }^{26}$ Captopril was shown to reduce blood pressure of SHR rats through reduction of vasoconstrictors angiotensin II and endothelin as well as by reducing the level of oxidants, which are abnormally sustained in SHR rats. ${ }^{27}$ Therefore, it is postulated that the possible reason for the selective reduction in blood pressure might be due to the mode of action of both oral S. polyanthum leaves extracts that counter-act the endothelial or vascular dysfunction present in the diseased SHR rat model, without affecting the normal condition in normotensive WKY rat model.

On contrary, the selective reduction in blood pressure by oral S. polyanthum leaves extract was not observed in our previous study when similar extracts were intravenously administered into anesthetized WKY and SHR rats. ${ }^{2}$ This discrepancy might be due to the use of different routes of administration in these studies. Our presumption was that the oral route of administration may affect the extracts by predisposing some of its active components to destruction by digestive enzymes or gastric fluids, or that some of its active components might be metabolized by enzymes or bacteria in the gastrointestinal tract before systemic absorption occurs. This aspect could have affected the bioavailability of the active components and this might in turn, impacted the resultant actions of the extracts. The underlying principles governing this finding remains to be further investigated.

Other than that, this study also showed that the effect by oral MESP was more prominent than oral ADSP during acute single-dose and sub-acute repeated-dose effect studies. When acutely administered, oral MESP caused significant SBP reduction at a dose of $2.00 \mathrm{~g} / \mathrm{kg}$, lower than oral $\operatorname{ADSP}(2.5 \mathrm{~g} / \mathrm{kg})$. During sub-acute effect study, oral MESP achieved significant SBP reduction as early as week 2, which was faster than oral ADSP that started to exhibit significant SBP reduction only by week 3 . Moreover, this effect by oral MESP at week 2 was able to sustain until week 3 . In corroboration with this finding, recent study by Ahmad et al. ${ }^{4}$ has also shown that their methanol extract which was prepared using ultrasound-assisted method caused significant reduction in blood pressure in SHR with structural improvement of its aorta and kidney when daily-treated for 6 weeks.

In addition, our study has shown that oral MESP and losartan, a standard antihypertensive drug had a comparable onset time of action and efficacy when treated daily for 3-week. According to Law et al., ${ }^{28}$ even $5 \mathrm{mmHg}$ reduction in blood pressure was already vital to cause significant decreases in the risk of stroke and ischemic heart disease by $34.00 \%$ and $21.00 \%$, respectively. In this study, MESP $(2.5 \mathrm{~g} / \mathrm{kg} / \mathrm{day})$ managed to cause a maximum reduction of SBP by $16.46 \pm 3.52 \mathrm{mmHg}$ while ADSP $(2.5 \mathrm{~g} / \mathrm{kg} / \mathrm{day})$ by $8.63 \pm 4.07 \mathrm{mmHg}$ after 3 -week of daily treatment. Even losartan potassium at a therapeutic dose of $0.01 \mathrm{~g} / \mathrm{kg} /$ day caused a maximum significant SBP reduction of $12.71 \pm 3.12 \mathrm{mmHg}$ after 3-week of daily treatment. Hence, the magnitude of blood pressure reduction

Table 4: Quantity of Gallic acid in ADSP and MESP.

\begin{tabular}{ccccccc}
\hline \multirow{2}{*}{$\begin{array}{c}\text { Extracts } \\
(10 \mathrm{mg} / \mathrm{ml})\end{array}$} & \multicolumn{3}{c}{ Concentration (ppm) } & $\begin{array}{c}\text { Average concentration (ppm) } \pm \text { SD } \\
\text { (per 10 mg sample) }\end{array}$ & $\begin{array}{c}\text { Concentration in } \\
\text { percentage of sample (w/w) }\end{array}$ \\
\cline { 2 - 4 } ADSP & 161.70 & 153.55 & 156.03 & $157.09 \pm 4.18$ & 1.57 \\
MESP & 141.32 & 126.75 & nun 2 & Run 3 & $134.04 \pm 10.30$ & 1.34 \\
\hline
\end{tabular}

Note: ADSP: Aqueous decoction of S. polyanthum leaves, MESP: Methanolic extract of S. polyanthum leaves, ppm: Parts per million, SD: Standard deviation, w/w: Weight over weight and $n . d$ : not determined. 


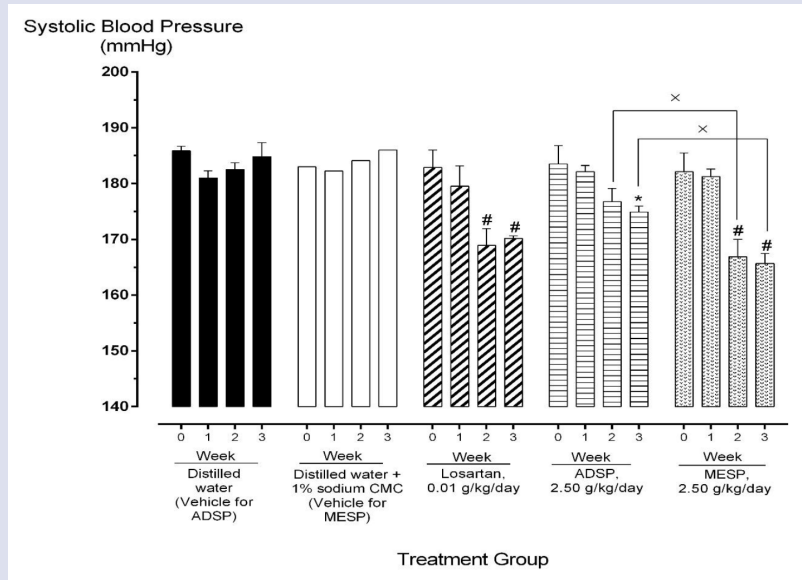

Figure 1: Sub-acute effect of vehicles, losartan, ADSP and MESP on SBP of SHR rats $(n=4)$ for a period of 3-week. SBP for week 0, 1, 2 and 3 imply SBP measured before experiment start and after first (day 8), second (day 15), and third (day 22) weeks. Results expressed as mean \pm S.E.M. ADSP: Aqueous decoction of S. polyanthum leaves, MESP: Methanolic extract of S. polyanthum leaves, CMC: carboxymethylcellulose, SBP: Systolic blood pressure, SHR: Spontaneously hypertensive rats, ${ }^{*}: P<0.05$ and \#: $P<0.001$, all vs. pre-treatment baseline value $(W=0), x: P<0.05, A D S P-v s$. MESP-treated group.

A

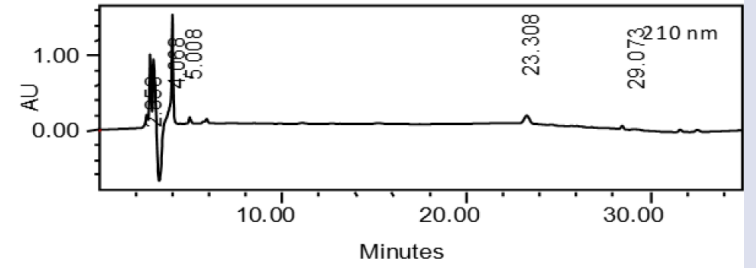

B

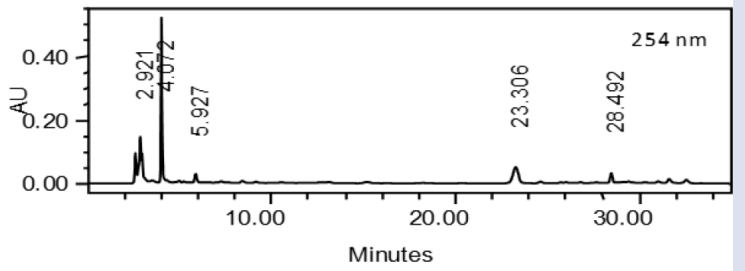

C

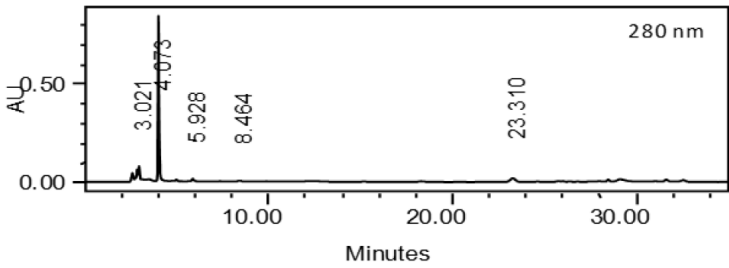

$\mathrm{D}$

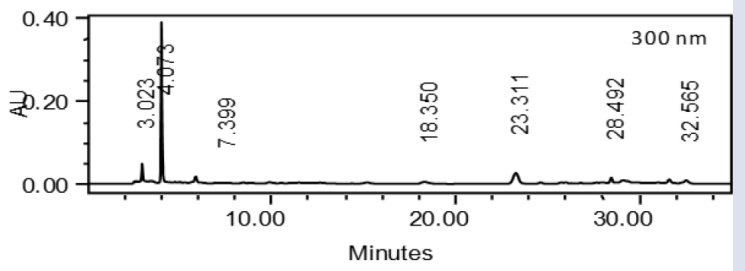

Figure 2: HPLC chromatograms of ADSP at the wavelengths of $A$ ) $210, B) 254$, C) 280 , D) and D) 300 . The $x$-axis represents time while the $\mathrm{y}$-axis represents the abundance. $\mathrm{AU}$ : Absorption units, and $\mathrm{nm}$ : Nanometre.

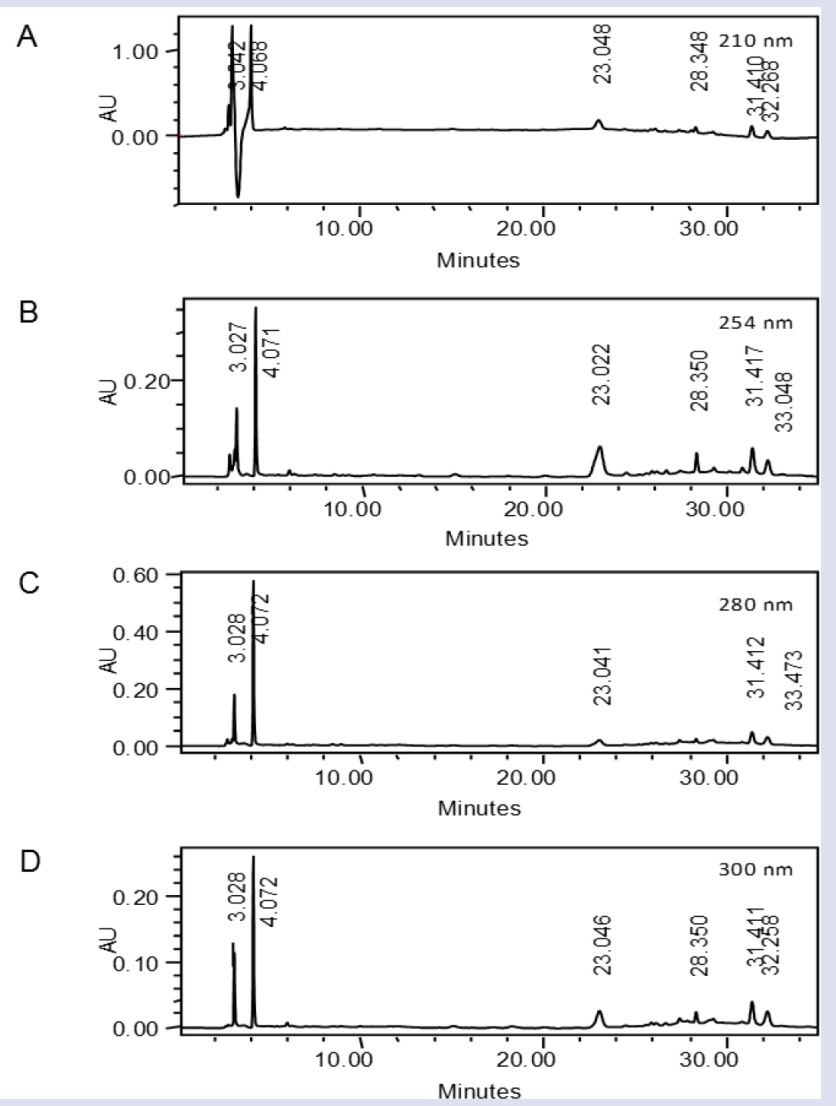

Figure 3: HPLC chromatograms of MESP at the wavelengths of A) 210, B) 254 , C) 280 and D) 300 . The $x$-axis represents time while the $y$-axis represents the abundance. AU: Absorption units, and nm: Nanometre.

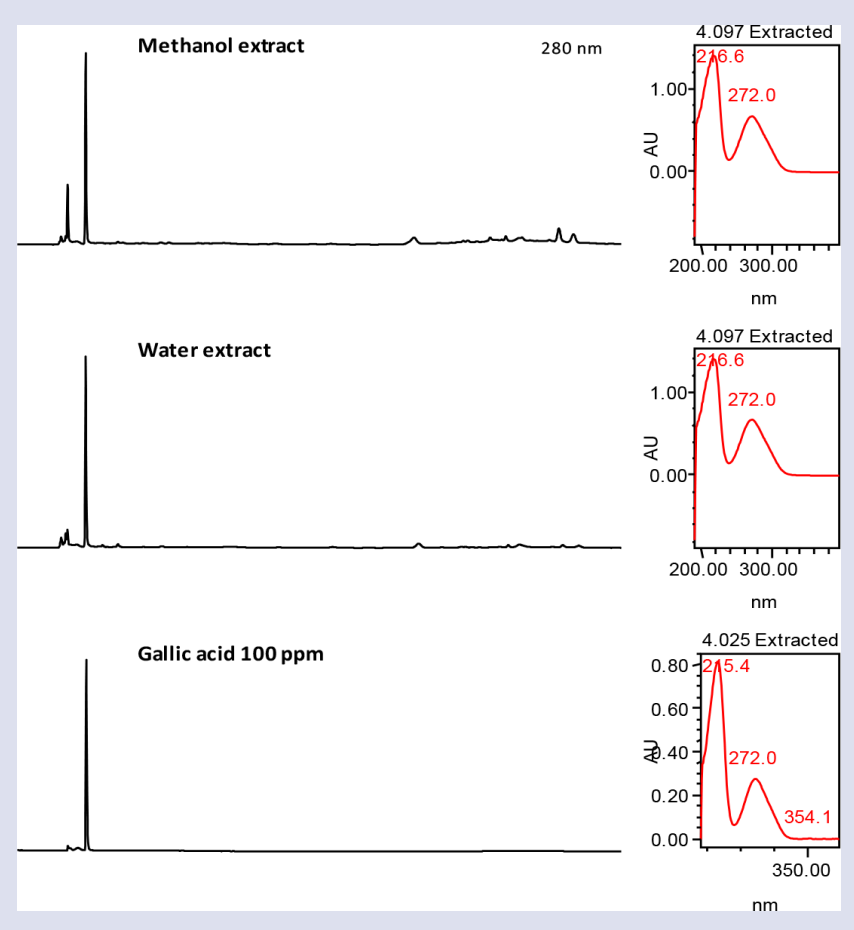

Figure 4: HPLC chromatograms of ADSP, MESP, and gallic acid (100 ppm) at $280 \mathrm{~nm}$. ppm: Parts per million, AU: Absorption units. 


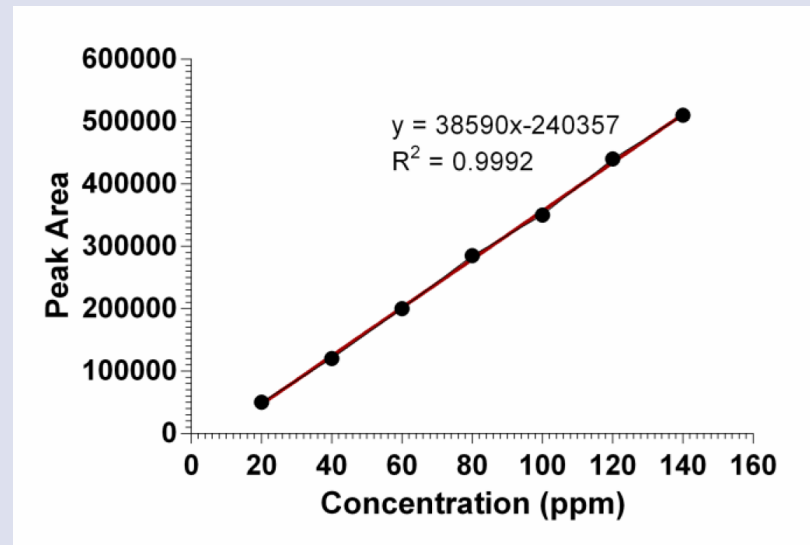

Figure 5: A standard curve for gallic acid. ppm: Parts per million. by oral S. polyanthum leaves extracts at $2.5 \mathrm{~g} / \mathrm{kg} /$ day was higher than the amount of blood pressure reduction which might reduce the risk of cardiovascular diseases

Apart from that, the phytochemical screening study had shown that both ADSP and MESP contained phenolics, as indicated by the strong and intense blue-black coloration of precipitate in ferric-chloride test. gallic acid was identified as a major peak in our HPLC chromatograms of ADSP and MESP with the quantity of $1.57 \%$ and $1.34 \%$, respectively. Therefore, this finding is well-corroborated with Har and Ismail ${ }^{10}$ whom has identified gallic acid as the major phenolic compounds in the crude methanolic extract of $S$. polyanthum leaves, prepared by percolation technique.

Gallic acid is a type of phenolic acids that exists in plant materials in the form of free acids, esters, catechin derivatives and hydrolysable tannins. ${ }^{29}$ In relation to antihypertensive effect, few studies has shown some direct and indirect evidences that may link gallic acid with blood pressure reduction. Butyl gallate, an ester of gallic acid reduced the blood pressure of normotensive rats when administered via intraperitoneal injection; more importantly, it also reduced the blood pressure of hypertensive rats when fed orally. ${ }^{30} \mathrm{~A}$ more recent study has shown that oral treatment with gallic acid for 4 weeks managed to normalize the systolic, diastolic and mean arterial blood pressures of diabetic rats. ${ }^{12}$ In addition, some in vitro studies have demonstrated renin-inhibitory activity and vasorelaxation effect by gallic acid. Li et al. ${ }^{13}$ reported that gallic acid possessed inhibitory activity towards renin, an important enzyme that can cleave the angiotensinogen to yield angiotensin I. This is the rate-limiting step in the production of angiotensin II, a potent vasoconstrictor. Thus, an inhibition of renin is suggested to suppress the production of angiotensin II, which in turn results in reduction of blood pressure. Few in vitro studies have further demonstrated the vasorelaxation effect by gallic acid ${ }^{14,15}$ which was mediated through nitric oxide/cGMP signaling pathway. Gallic acid may act as a potassium channel opener and also as a calcium channel blocker to cause vasorelaxation. ${ }^{15}$ The resultant vasorelaxation effect may reduce the total peripheral resistance resulting in reduction of blood pressure. Interestingly, our recent study has shown that the aqueous and methanolic extract of $S$. polyanthum leaves extract have some vasorelaxation properties when tested on isolated thoracic aorta rings of WKY and SHR rats. ${ }^{3}$ Altogether, these previous studies on gallic acid may suggest for its contribution to blood pressure reducing activity by $S$. polyanthum leaves extracts towards a certain extent.
Nonetheless, our finding showed that gallic acid was present in higher percentage in ADSP than in MESP, but the blood pressure-reducing capability by oral MESP was more significant compared to ADSP. Thus, it is postulated that gallic acid might have some possible interactions with other compound(s) for the net effect. Therefore, it is strongly recommended to proceed with a more definitive study such as bioassay-guided fractionation and isolation of the bioactive compounds in future.

\section{CONCLUSION}

This study showed that both oral aqueous decoction and methanol extract of $S$. polyanthum leaf significantly reduced blood pressure of spontaneously hypertensive rats, but not of normotensive Wistar-Kyoto rats. However, the antihypertensive effect by its methanol extract was found to be more prominent than the aqueous decoction when administered orally. Both aqueous decoction and methanol extract contain gallic acid as the major phenolic compound.

\section{ACKNOWLEDGEMENT}

This study is funded by Ministry of Higher Education Malaysia through Short-Term Grant (304/PPSK/61312059) from University Sains Malaysia and Research Initiative Grant Scheme (RIGS-15-039-0039) from International Islamic University Malaysia.

\section{CONFLICT OF INTEREST}

There are no conflicts of interest.

\section{ABBREVIATIONS}

ADSP: Aqueous decoction of S. polyanthum leaves; MESP: Methanolic extract of S. polyanthum leaves; WKY: Wistar-Kyoto rats; SHR: Spontaneously hypertensive rats; SBP: Systolic blood pressure.

\section{REFERENCES}

1. Kato $E$, Nakagomi R, Gunawan-Puteri M, Kawabata J. Identification of hydroxychavicol and its dimers, the lipase inhibitors contained in the Indonesian spice, Eugenia polyantha. Food Chem. 2013:136(3-4):1239-42.

2. Ismail A, Mohamed M, Sulaiman S, Wan Ahmad W. Autonomic nervous system mediates the hypotensive effects of aqueous and residual methanolic extracts of Syzygium polyanthum (Wight) Walp. var. polyanthum leaves in anaesthetized rats. Evid-Based Complement Alternat Med. 2013:2013:1-17.

3. Ismail A, Ahmad WANW. Autonomic receptors and nitric-oxide involvements in mediating vasorelaxation effect induced by Syzygium polyanthum leaves extract. Pharmacogn Res. 2017:9(1):S9-S14.

4. Ahmad WW, Jamal N, Rahmat U, Ramli N, Muhammad N, Noordin L. Evaluation of Syzygium polyanthum leaves methanol extract as antihypertensive agent in rat. Int J Cardiol. 2017:249:S10.

5. Ramli N, Muhammad N, Safuan, Noordin L, Wan Ahmad WAN. Preliminary evaluation on the effect of methanolic extract from Syzygium polyanthum on improvement of hypertensive-renal damage among Spontaneous Hypertensive Rat models. Annals of Microsc. 2017:16:15-22.

6. Ichimura T, Yamanaka A, Ichiba T, Toyokawa T, Kamada Y, Tamamura T, et al. Antihypertensive effect of an extract of Passiflora edulis rind in spontaneously hypertensive rats. Biosci, Biotechnol Biochem. 2006:70(3):718-21.

7. Lv GY, Zhang YP, Gao JL, Yu JJ, Lei J, Zhang ZR, et al. Combined antihypertensive effect of luteolin and buddleoside enriched extracts in spontaneously hypertensive rats. J Ethnopharmacol. 2013:150(2):507-13.

8. Widyawati T, Yusoff NA, Asmawi MZ, Ahmad M. Antihyperglycemic effect of methanol extract of Syzygium polyanthum (Wight.) leaf in streptozotocin-induced diabetic rats. Nutrients. 2015:7(9):7764-80.

9. Kusuma IW, Kuspradini H, Arung ET, Aryani F, Min YH, Kim JS, et al. Biological activity and phytochemical analysis of three Indonesian medicinal plants, Mur raya koenigii, Syzygium polyanthum and Zingiber purpurea. J Acupunct Meridian Stud. 2011:4(1):75-9

10. Har L, Ismail I. Antioxidant activity, total phenolics and total flavonoids of Syzygium polyanthum (Wight) Walp leaves. Int J Med Arom Plant. 2012:2(2):219-28.

11. Hamad A, Mahardika MGP, Istifah I, Hartanti D. Antimicrobial and volatile compounds study of four spices commonly used in Indonesian culinary. J Food Pharm Sci. 2016:4(1):1-5.

12. Mantruad A, Pannangpetch $P$, Kongyingyoes B, Kukongviriyapan U, Chuanta S, 
Nakmareong S, et al. Roselle extract and Gallic acid improve vascular reactivity of diabetic rats. Srinagarind Med J. 2010:25:257-61.

13. Li F, Takahashi Y, Yamaki K. Inhibitory effect of catechin-related compounds on renin activity. Biomed Res. 2013:34(3):167-71.

14. Gil-Longo J, Gonzalez-Vazquez C. Vascular pro-oxidant effects secondary to the autoxidation of Gallic acid in rat aorta. J Nutr Biochem. 2010:21(4):304-9.

15. De Oliveira LM, De Oliveira TS, Da Costa RM, De Souza Gil E, Costa EA, Passaglia RdCAT, et al. The vasorelaxant effect of Gallic acid involves endotheliumdependent and-independent mechanisms. Vascul Pharmacol. 2016:81:69-74.

16. Malkoff J. About mouse and rat tail cuff-method non invasive blood pressure Animal Lab News. 2005. [updated 2005 October 31; cited 2018 February 27] Available from: https://www.alnmag.com/article/2005/10/non-invasive-bloodpressure-mice-and-rats.

17. Tom E, Girard-Thernier C, Martin H, Dimo T, Alvergnas M, Nappey M, et al. Treatment with an extract of Terminalia superba Engler and Diels decreases blood pressure and improves endothelial function in spontaneously hypertensive rats. J Ethnopharmacol. 2014:151(1):372-9.

18. Ng C, Koona C, Cheunga D, Lama M, Leunga $P$, Laua $C$, et al. The anti-hypertensive effect of Danshen (Salvia miltiorrhiza) and Gegen (Pueraria lobata) formula in rats and its underlying mechanisms of vasorelaxation. J Ethnopharmacol. 2011:137(3):1366-72

19. Maghrani M, Zeggwagh N, Michel J, Eddouks M. Antihypertensive effect of Lepidium sativum L. In spontaneously hypertensive rats. J Ethnopharmacol. 2005:100(1-2):193-97.

20. Eddouks M, Maghrani M, Zeggwagh N-A, Haloui M, Michel J-B. Fraxinus excelsior L. evokes a hypotensive action in normal and spontaneously hypertensive rats. J Ethnopharmacol. 2005:99(1):49-54

21. Ashraf MS, Vongpatanasin W. Estrogen and hypertension. Curr Hypertens Rep. 2006:8(5):368-76.

22. Abraham HMA, White CM, White WB. The comparative efficacy and safety of the angiotensin receptor blockers in the management of hypertension and other cardiovascular diseases. Drug Saf. 2015:38(1):33-54.

23. Turner P, Brabb T, Pekow C, Vasbinder M. Administration of substances to laboratory animals: Routes of administration and factors to consider. J Am Assoc Lab Anim Sci. 2011:50(5):600-13.

24. Raaman N. Phytochemical techniques. New Delhi: New India Publishing. 2006

25. Rangari VD. Pharmacognosy and phytochemistry Volume 1. Maharashta: Career publications. 2009.

26. Duarte J, Pérez-Palencia R, Vargas F, Angeles Ocete M, Pérez-Vizcaino F Zarzuelo $A$, et al. Antihypertensive effects of the flavonoid quercetin in spontaneously hypertensive rats. Br J Pharmacol. 2001:133(1):117-24.

27. Bolterman RJ, Manriquez MC, Ruiz MCO, Juncos LA, Romero JC. Effects of captopril on the renin angiotensin system, oxidative stress, and endothelin in normal and hypertensive rats. Hypertension. 2005:46(4):943-47.

28. Law M, Wald N, Morris J. Lowering blood pressure to prevent myocar dial infarction and stroke: A new preventive strategy. Health Technol Assess. 2003:7(31):1-109.

29. Karamac M, Kosinska A, Pegg R. Content of Gallic acid in selected plant ex tracts. Pol J Food Nutri Sci. 2006:15(1):55-8.

30. Cash W. Production of an hypotensive effect with esters of Gallic acid. United States of America Patent 3784695. 1974.

\section{GRAPHICAL ABSTRACT}

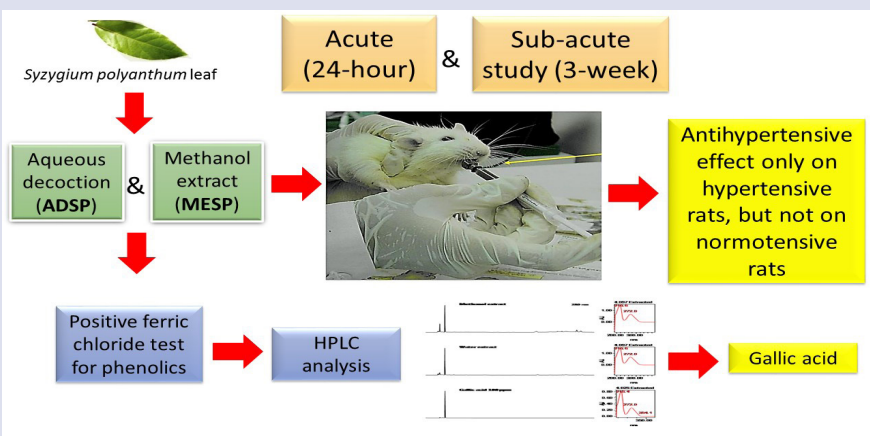

\section{SUMMARY}

- Oral administration of aqueous decoction and methanol extract of Syzygium polyanthum leaves that contain gallic acid causes acute and sub-acute antihypertensive effects in SHR.

- The methanol extract was found to be more prominent than the aqueous decoction.

- No significant effect seen on normal rats.

\section{ABOUT AUTHORS}

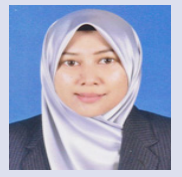

Azlini Ismail: Is currently an Assistant Professor in the field of Pharmacology at Department of Fundamental Dental and Medical Sciences, Kulliyyah of Dentistry, International Islamic University Malaysia.

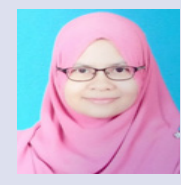

Nurul Syahida Ramli: Is currently a PhD student in Pharmacology at School of Health Sciences, Universiti Sains Malaysia.

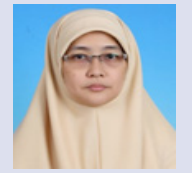

Mahaneem Mohamed: Is an Associate Professor at Physiology Department, School of Medical Sciences, Universiti Sains Malaysia.

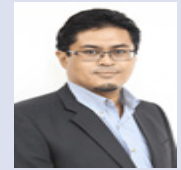

Wan Amir Nizam Wan Ahmad: Is currently holding a post as a senior medical lecturer in Pharmacology and Biostatistics at School of Health Sciences, Universiti Sains Malaysia.

Cite this article: Ismail A, Ramli NS, Mohamed M, Ahmad WANW. Acute and Sub-Acute Antihypertensive Effects of Syzygium polyanthumLeaf Extracts with Determination of Gallic Acid using HPLC Analysis. Pharmacog J. 2018;10(4):663-71. 